\title{
CORRESPONDENCE
}

\section{Mortality rate in Polish intensive care units is lower than predicted according to the APACHE II scoring system}

\author{
Piotr Knapik ${ }^{1 *}$, Łukasz J. Krzych² ${ }^{2}$ Wojciech Weigl ${ }^{3}$, Jan Adamski ${ }^{4}$ and Michael Hultstöm ${ }^{3,5}$
}

(0) 2017 The Author(s). This article is an open access publication

\section{Initial correspondence from Drs. Knapik and Krzych}

Dear Editor,

We read with interest the letter recently published by Weigl et al. in Intensive Care Medicine [1]. Based on the information in this letter, the reader may assumewrongly - that the level of intensive care unit (ICU) services in Poland is insufficient to guarantee optimal patient care. However, higher mortality in Polish ICUs is in fact due to profound differences in patient populations, availability of ICU beds, indications for ICU admission and organisation of end-of-life care in Poland, in comparison to other European countries. Additionally, the official Polish Society guidelines on futile therapy [2] and on criteria of ICU admission are still ignored by many intensivists due to uncertainity regarding the legal consequences and/or pressure from other departments and the hospital administration.

Based on our analysis of data from the Silesian Registry of Intensive Care Units [3], we can clearly demonstrate that many patients admitted to Polish ICUs were at the highest risk of death but that ICU mortality was even lower than that predicted by the APACHE II scoring system, especially within the highest values (Fig. 1). Overall predicted mortality for this population was $47 \%$ and the observed-to-predicted mortality ratio was 0.93 .

In summary, interpretation of demographic indices across countries must always be performed with extreme caution and with taking into account all potential

\footnotetext{
*Correspondence: kardanest@sum.edu.pl

${ }^{1}$ Department of Cardiac Anesthesia and Intensive Care, Silesian Centre of Heart Diseases, Medical University of Silesia, Zabrze, Poland Full author information is available at the end of the article
}

confounders. We fully support the notion of Weigl et al. to stimulate improvement of critical care services in Poland and expanding the already existing regional database to a national registry.

\section{Reply from Drs. Weigl, Adamski and Hultstöm}

We would like to thank Professor Knapik and Professor Krzych for their comments based on data from the Silesian Registry of Intensive Care Units in Poland. The high mortality rates obtained from the Polish ICUs cited in our letter [1] does indeed call into question issues such as quality of care and end-of-life guidelines. The data on a large number of mechanically ventilated patients, high severity of illness scores, and satisfactory ratio of observed to predicted mortality, which have been reported by Knapik and Krzych, contribute to the discussion on both the potential risk factors and level of service, and are in line with our previous findings [4]. As such, we agree that the high mortality rates in Polish ICUs cannot be simply interpreted as results of low quality of care.

In addition, we are aware that the Polish guidelines regarding ICU triage have been published. However, as Knapik and Krzych noted, the extent to which these are being followed is unknown. The important point we wished to make is that these guidelines are not supported by either Polish legislation or by the organization of endof-life care in Poland.

In conclusion, the reasons for high ICU mortality in Poland need to be further investigated and should be addressed properly. We are encouraged by the activity of the Silesian regional ICU registry and look forward to publication of their results. However, we are confident that the future development of intensive care in Poland requires a national registry that could provide an 


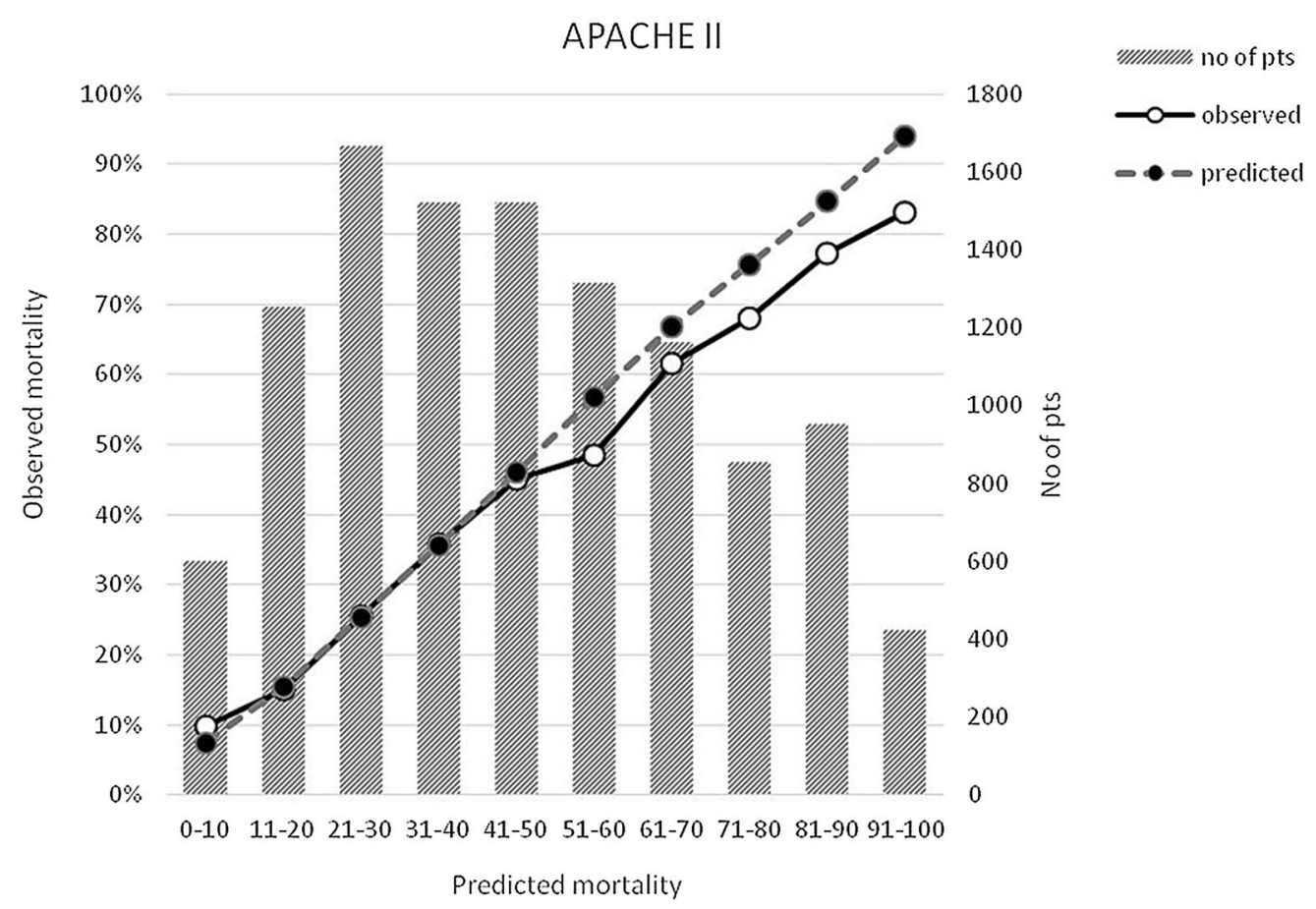

Fig. 1 Predicted-to-observed mortality ratio in the Silesian Registry of Intensive Care Units. APACHE I/ Acute Physiology and Chronic Health Evaluation II

impetus for change in Polish legislation and healthcare organization.

\section{Author details}

${ }^{1}$ Department of Cardiac Anesthesia and Intensive Care, Silesian Centre of Heart Diseases, Medical University of Silesia, Zabrze, Poland. ${ }^{2}$ Department of Anaesthesiology and Intensive Care, Medical University of Silesia, Katowice, Poland. ${ }^{3}$ Anaesthesiology and Intensive Care, Department of Surgical Sciences, Akademiska Hospital, Uppsala University, 75185 Uppsala, Sweden. ${ }^{4}$ Department of Anaesthesia and Intensive Care, Satakunta District Hospital, 28500 Pori, Finland. ${ }^{5}$ Integrative Physiology, Department of Medical Cellbiology, Uppsala University, 75123 Uppsala, Sweden.

\section{Compliance with ethical standards}

\section{Conflicts of interest}

The authors declare that they have no competing interests.

\section{Open Access}

This article is distributed under the terms of the Creative Commons Attribution-NonCommercial 4.0 International License (http://creativecommons.org/ licenses/by-nc/4.0/), which permits any noncommercial use, distribution, and reproduction in any medium, provided you give appropriate credit to the original author(s) and the source, provide a link to the Creative Commons license, and indicate if changes were made.
Accepted: 1 July 2017

Published online: 21 July 2017

\section{References}

1. Weigl W, Adamski J, Goryński P, Kański A, Hultström M (2017) Mortality rate is higher in Polish intensive care units than in other European countries. Intensive Care Med. doi:10.1007/s00134-017-4804-2

2. Kübler A, Siewiera J, Durek G, Kusza K, Piechota M, Szkulmowski Z (2014) Guidelines regarding the ineffective maintenance of organ functions (futile therapy) in ICU patients incapable of giving informed statements of will. Anaesthesiol Intensive Ther 46:215-220. doi:10.5603/AIT. a2014.0038

3. Krzych $七 J$, Czempik PF, Kucewicz-Czech E, Knapik P (2017) Silesian registry of intensive care units. Anaesthesiol Intensive Ther 49:73-75. doi:10.5603/ AlT.2017.0011

4. Adamski J, Goraj R, Onichimowski D, Gawlikowska E, Weigl W (2015) The differences between two selected intensive care units located in central and northern Europe — preliminary observation. Anaesthesiol Intensive Ther 47:117-124 